\title{
Innovative professional learning in early childhood education and care: Inspiring hope and action
}

\author{
Joanne Lehrer, Christine Massing, and Alaina Roach O’Keefe
}

\section{Dear colleagues,}

It is with great pleasure that we present you with this bilingual special issue of the Journal of Childhood Studies focused on innovative professional learning in early childhood education and care. This special issue arose out of the Canadian Association for Research in Early Childhood's post-conference on the same theme, presented following the Society for Studies in Education's 2017 conference at Ryerson University in Toronto.

Not only is professional learning conceptualized as critical for increasing educational quality and enhancing children's learning and developmental outcomes (e.g., Lazarri, Picchio, \& Musatti, 2013; Munton et al., 2002; Peleman et al., 2017; Penn, 2009; Vandenbroeck, Peeters, Urban, \& Lazarri, 2016), but specific elements of professional learning (in both initial and continuing education, or preservice and in-service learning) have been identified as essential to transforming early childhood educators' and preschool teachers' professional identities and practice. For example, critical and supported reflection (Thomas \& Packer, 2013), learning experiences that target entire teams (Vangrieken, Dochy, \& Raes, 2016), collaborative and empowering practice (Helterbran \& Fennimore, 2004), long-term interventions (Peleman et al., 2017), and competent leadership (Colmer, Waniganayake, \& Field, 2008) have all been found to be effective means of supporting professional learning.

While there appears to be consensus in the literature around what needs to be done, and even around how it should be done, numerous constraints prevent the implementation and maintenance of sustainable and transformational professional learning in ECEC. Michel Vandenbroeck and his colleagues (2016) go beyond the focus on individuals and childcare teams, identifying two further levels necessary for competent systems of professional learning: partnerships between local early childhood programs and social, cultural, and educational institutions (such as colleges and universities); and governance regarding vision, finance, and monitoring. In the Canadian context, the Canadian Child Care Federation (2016) also stresses the importance of a system-wide strategy to strengthen the childcare workforce. However, early childhood services in Canada are under the purview of provincial and territorial governments, and therefore the conditions, regulations, certification requirements, curriculum documents, and educational systems vary widely from jurisdiction to jurisdiction. The educational requirements for certification, for example, may include no formal training (in Northwest Territories and Nunavut), one entry-level short course, one-year certificates, or two-year diplomas. Some provinces also offer three- or four-year bachelor-level university programs. This diversity of pathways complicates efforts to define who the early childhood professional is and what opportunities are constitutive of professional learning (Prochner, Cleghorn, Kirova, \& Massing, 2016). While these disparities within the field may impede the development of a cohesive strategy, much can be learned from sharing and appreciating the rich diversity of approaches to professional learning both within and across provinces and territories, as Carol Campbell and her colleagues (2016) assert. In addition, examples from other countries serve to broaden the discussion and expand our understanding of what is possible (Peleman et al., 2017; Vandenbroeck et al., 2016).

This special issue, then, is dedicated to sharing stories of hope and coordinated action, linking theory with practice. The articles present research at the individual, team, partnership, and governance levels (Vandenbroeck et al., 2016), focusing on both preservice and in-service professional learning. 
Claire Moreau, Nicole Royer, and Chantal Royer recount narratives of educators registered in an online university certificate program. Their analysis traces the stages the educators encounter as they embark on this learning journey, from being intimidated by the university and attempting to find balance between work, study, and family, to reflecting on their learning and their learning community, and finally to personal and professional transformation they attribute to their experience. Specific challenges relating to the online nature of the program are discussed, such as access to virtual resources once each course is over and not being able to physically recognize their online instructors. The process is presented as a story, with each new stage unfolding through the participants' voices and deep conceptual analysis. The discussion targets program directions and puts forward practical suggestions to better meet the needs of nontraditional university students.

Alaina Roach O'Keefe, Sonya Hooper, and Brittany Jakubiec explore how experienced early childhood educators from Prince Edward Island define their professionalism in a context where new initiatives and policy changes have contributed to corresponding shifts in roles and expectations. They contend that system changes, such as the schoolification of kindergarten and a push for increased documentation learning, had both positive and negative impacts on these educators, but ultimately caused some of them to lose their professional confidence. The findings suggest a need for workplace resilience and wellness initiatives, professional recognition, and professional learning opportunities around topics such as leadership and pedagogical documentation.

In "Animating a Curriculum Framework Through Educator Co-Inquiry: Co-Learning, Co-Researching, and CoImagining Possibilities," Jane Hewes, Patricia Lirette, Lee Makovichuk, and Rebekah McCarron share ongoing participatory research that explores pedagogical mentoring and educator co-inquiry as an approach to transforming early childhood educator practice and "reinvigorating" relationships in the early childhood field. Storytelling is central to meaning making in this project that renewed curiosity and critical pedagogical reflection, empowering educators to bring curriculum frameworks to life through their work with young children. Fundamental notions of critical reflection on emergent curriculum, documentation, and the cyclical process involved in co-inquiry are conceptualized as paramount to the field.

Joane Deneault and Odette Lefebvre focus on a partnership established in the Bas-St-Laurent region of Québec that includes community organizations, representatives of various government ministries, and institutes of higher learning. Their article tells the story of how the partnership supported a continuing education program aimed at early childhood educators and kindergarten teachers and focused on children's emotional well-being. In it they describe the tensions among discourses of deficit when it comes to child development, programs that aim to instill a pedagogy of listening, and relationships between adults and young children, as well as how the partnership coped with budget cuts in order to maintain the project.

In "Finding Community: An Exploration into an Induction Support Pilot Project," Laura Doan shares the perspectives of new and experienced early childhood educators in British Columbia, noting that peer mentoring programs can create a professional learning community of practice that fosters connections to the community, increased knowledge, and a sense of efficacy. The program's success was attributed to the educators' active involvement in co-constructing the program structure and to their long-term engagement with one another to dialogue about important issues in their own practice.

In "Navigating Power and Subjectivity: Cultural Diversity and Transcultural Curriculum in Early Childhood Education," Carolyn Bjartveit and Cheryl Kinzel dialogically reflect on how they might interrogate and disrupt the dominant discourse through their involvement in a professional learning community (PLC) in Alberta. The authors acknowledge their own privilege and subjectivities in their professional roles, situating themselves in the context of this discourse to envision ways for their PLC to foreground diverse perspectives that are typically 
marginalized or excluded in the field.

Hélène Larouche, Diane Biron, and Julie Vaillancourt relate a three-year journey of professional learning with kindergarten teachers focused on a community of practice around active learning, which was designed not to "fill gaps or lacks in teacher knowledge, but to affirm and consolidate the act of teaching by focusing on their reflexive capacities." Their retrospective analysis of the teachers' engagement in the professional learning process identifies both strengths and challenges of the experience focused on creating a culture of collaboration. They conclude by reflecting on the difficulties of the process for both the teachers and the research team.

In "Learning Collectives With/In Sites of Practice: Beyond Training and Professional Development," Kathleen Kummen and B. Denise Hodgins share their research grounded in social constructivist learning on pedagogical development. The article describes an initiative that extended the Investigating Quality (IQ) Project's model of pedagogical development to a partnership between local ECE programs and their ongoing professional learning and an ECE training institution and its preparation of student educators. Grounding the study in investigating how it conceptualizes and promotes professional learning as co-constructed in socio-material-historical-culturalpolitical contexts, they analyze the model based on three conditions: inquiry-based learning, making learning visible, and pedagogical facilitation support. They argue the model is equally important and pertinent to both early and ongoing professional development in the field, and that a commitment to learning collectives is essential as we move forward in professionalizing the EC field.

Drawing on their own experiences, Michelle Jones, Brooke Richardson, and Alana Powell describe how their experiences have motivated them to become student leaders engaged in the childcare advocacy movement at the grassroots level. In "Reconceptualizing Our Work: The Connection Between Early Childhood Education Students and Political Action," they argue that sustaining student movements requires not only interest on the part of students, but also an academic culture and structure that supports advocacy groups. To produce sustainable student advocacy groups, institutions must guide students in identifying and problematizing the systemic neoliberal policies that function to devalue educators' work.

In "Professional Knowledges for Early Childhood Education and Care," Verity Campbell-Barr challenges a hegemonic discourse of professional knowledge that includes technocratic discourses relating to quality, "selective representations of neuroscience," and the economic investment narrative. Instead, she draws on Bernstein's conceptualization of vertical and horizontal knowledges, as well as Aristotle's three forms of knowledge-episteme (pure knowledge), techne (skills) and phronesis (practical wisdom)-to reconceptualize a pluralized concept of professional knowledges in ECEC, with a particular focus on the reflexive and considered nature of practical wisdom. She also critiques "rogue theories," such as the gendered ideal of women as innately caring.

We hope this collection of articles provides fruit for reflection, inspiration, and new questions about professional learning at multiple levels and in diverse contexts.

We extend our appreciation to all of our reviewers, who generously shared their time and expertise with us and with the authors. We also thank editorial assistants Dr. Nicole Land and Meagan Montpetit for their patient and invaluable assistance throughout the process, as well as Leslie Prpich and Marie-Christine Payette for their copyediting assistance. 


\section{References}

Campbell, C., Osmond-Johnson, P., Faubert, B., Zeichner, K., Hobbs-Johnson, A. with S. Brown, P. DaCosta, A. Hales, L. Kuehn, J. Sohn, \& K. Steffensen (2016). The state of educators' professional learning in Canada. Oxford, OH: Learning Forward.

Canadian Child Care Federation. (2016). An early learning and child care framework for Canada's children: \#TogetherWeCan. Retrieved from http://www.cccf-fcsge.ca/wp-content/uploads/CCCF_Framework-ENG.pdf

Colmer, K., Waniganayake, M., \& Field, L. (2014). Leading professional learning in early childhood centres: Who are the educational leaders? Australasian Journal of Early Childhood, 39(4), 103-113.

Helterbran, V. R., \& Fennimore, B. S. (2004). Early childhood professional development: Building from a base of teacher investigation. Early Childhood Education Journal, 31(4), 267-271.

Lazarri, A., Picchio, M., \& Musatti, T. (2013). Sustaining ECEC quality through continuing professional development: Systemic approaches to practitioners' professionalization in the Italian context. Early Years, 33(2), 133-145.

Munton, T., Mooney, A., Moss, P., Petrie, P., Clark, A., Woolner, J., et al. (2002). Research on ratios, group size, and staff qualifications and training in early years and childcare settings. London, UK: University of London.

Peleman, B., Lazzari, A., Budginaite, I., Siarova, H., Hauari, H., Peeters, J., \& Cameron, C. (2017). Continuous professional development and ECEC quality: Findings from a European systematic literature review. European Journal of Education, 53(1), 9-22. doi:10.1111/ejed.12257

Penn, H. (2009). Early childhood education and care: Key lessons from research for policy makers. Brussels, Belgium: Nesse.

Prochner, L., Cleghorn, A., Kirova, A., \& Massing, C. (2016). Teacher education in diverse settings: Making space for intersecting worldviews. Rotterdam, The Netherlands: Sense.

Thomas, S., \& Packer, D. S. (2013). A reflective teaching road map for pre-service and novice early childhood educators. International Journal of Early Childhood Special Education, 5(1), 1-14.

Vandenbroeck, M., Peeters, J., Urban, M., \& Lazzari, A. (2016). Introduction. In M. Vandenbroeck, M. Urban, \& J. Peeters (Eds.), Pathways to professionalism in early childhood education and care (pp. 1-14). London, UK: Routledge.

Vangrieken, K., Dochy, F., \& Raes, E. (2016). Team learning in teacher teams: Team entitativity as a bridge between teams-in-theory and teams-in-practice. European Journal of Psychology of Education, 31(3), 275-298. doi:10.1007/s10212-015-0279-0 